\title{
Impact of the 21-gene recurrence score assay on chemotherapy decision making and outcomes for breast cancer patients with four or more positive lymph nodes
}

\author{
Qing-Hong Zhang ${ }^{1 \#}$, Wen-Wen Zhang ${ }^{2 \#}$, Jun Wang ${ }^{3}$, Chen-Lu Lian ${ }^{3}$, Jia-Yuan Sun ${ }^{2}$, Zhen-Yu He ${ }^{2}$, \\ San-Gang $\mathrm{Wu}^{3}$
}

${ }^{1}$ Department of Anesthesiology, the First Affiliated Hospital of Xiamen University, Xiamen 361003, China; ${ }^{2}$ Department of Radiation Oncology, Sun Yat-sen University Cancer Center, State Key Laboratory of Oncology in South China, Collaborative Innovation Center of Cancer Medicine, Guangzhou 510060, China; ${ }^{3}$ Department of Radiation Oncology, Cancer Hospital, the First Affiliated Hospital of Xiamen University, Teaching Hospital of Fujian Medical University, Xiamen 361003, China

Contributions: (I) Conception and design: SG Wu, QH Zhang, WW Zhang, ZY He; (II) Administrative support: QH Zhang, SG Wu, ZY He; (III) Provision of study materials or patients: SG Wu; (IV) Collection and assembly of data: SG Wu, ZY He; (V) Data analysis and interpretation: J Wang, CL Lian, JY Sun; (VI) Manuscript writing: All authors; (VII) Final approval of manuscript: All authors.

"These authors contributed equally to this work.

Correspondence to: Zhen-Yu He. Department of Radiation Oncology, Sun Yat-sen University Cancer Center, State Key Laboratory of Oncology in South China, Collaborative Innovation Center of Cancer Medicine, 651 Dongfeng Road East, Guangzhou 510060, China. Email: hezhy@sysucc.org.cn; San-Gang Wu. Department of Radiation Oncology, Cancer Hospital, the First Affiliated Hospital of Xiamen University, Teaching Hospital of Fujian Medical University, Xiamen 361003, China. Email: unowu12345@hotmail.com.

Background: To assess the impact of the 21-gene recurrence score (RS) on chemotherapy decision making and survival outcomes for breast cancer patients with $>4$ positive lymph nodes.

Methods: Patients with non-metastatic estrogen receptor-positive breast cancer with $>4$ positive lymph nodes diagnosed between 2004 and 2013 were identified using the Surveillance, Epidemiology, and End Results database. The relationships between the 21-gene RS value and survival outcomes, chemotherapy decision-making, and chemotherapy benefit were analyzed.

Results: A total of 410 patients were identified, including 191 (46.6\%), 164 (40.0\%), and 55 (13.4\%) in the low-, intermediate-, and high-risk RS groups, respectively. The 21-gene RS assay results were independently related to chemotherapy receipt. A total of $59.0 \%, 68.0 \%$, and $78.0 \%$ of patients received chemotherapy in the low-, intermediate-, and high-risk RS groups, respectively. The 21-gene RS was an independent indicator of breast cancer specific survival (BCSS) and overall survival (OS). Intermediate-risk [BCSS: hazards ratio (HR), 2.832, 95\% confidence interval (CI): 1.160-6.910, P=0.022; OS: HR, 3.704, 95\% CI: 1.750-7.836, $\mathrm{P}=0.001$ ] and high-risk RS (BCSS: HR, 6.440, 95\% CI: 2.597-15.974, $\mathrm{P}<0.001$; OS: HR, 5.053, 95\% CI: 2.199-11.608, $\mathrm{P}<0.001)$ cohorts had significantly lower survival outcomes compared to low-risk RS cohort. The 5-year BCSS were $92.7 \%, 88.3 \%$, and 70.7\% in patients in the low-, intermediate-, and high-risk RS cohorts, respectively $(\mathrm{P}<0.001)$, and the 5 -year OS were $92.1 \%, 80.6 \%$, and $66.6 \%$, respectively $(\mathrm{P}<0.001)$.

Conclusions: The 21-gene RS is an independent predictor of chemotherapy receipt and survival outcomes for breast cancer patients with $>4$ positive lymph nodes.

Keywords: Breast neoplasms; Oncotype; clinical decision-making; lymph node; survival

Submitted May 11, 2019. Accepted for publication Aug 08, 2019.

doi: $10.21037 /$ atm.2019.08.82

View this article at: http://dx.doi.org/10.21037/atm.2019.08.82 


\section{Introduction}

Oncotype (Genomics Health, Inc., Redwood City, CA, USA) is a widely used gene-expression profiling method that measures quantitatively the expression of 21 genes in breast cancer using a reverse transcriptase polymerase chain reaction platform (RT-PCR) (1-3). Oncotype uses a continuous recurrence score (RS) to provide prognostic and predictive information for patients with node negative (N0) and estrogen receptor-positive (ER+), early stage breast cancer $(1,2)$. Several international cancer organizations including American Society of Clinical Oncology, European Society for Medical Oncology (ESMO), St. Gallen International Expert Consensus, and National Comprehensive Cancer Network (NCCN) have recommended the 21-gene RS as a biomarker to identify the risk for distant metastasis and to determine the effect of chemotherapy in patients with N0, N1mi $(\leq 2 \mathrm{~mm}$ lymph node metastasis), and N1 disease (less than 4 positive lymph nodes) (4-7).

Axillary lymph node status is an important indicator to guide the treatment of breast cancer. Patients with nodal positive $(\mathrm{N}+)$ disease have lower survival compared with those with N0 disease. However, a previous study from the Genomic Health laboratory included 610,350 breast tumor specimens, and the results showed that the distribution of 21-gene RS was similar for patients of N0, N1mi, and $\mathrm{N}+$ disease (8). Therefore, the same biological spectrum might exist in patients with $\mathrm{N} 0$ and $\mathrm{N}+$ disease. However, it remains unclear whether nodal metastasis is simply a sign of tumor progression over time or the metastatic capacity of the primary tumor is predetermined by tumor biology.

In patients with $\mathrm{N} 1$ disease, the observed differences in breast cancer specific survival (BCSS) with chemotherapy in low-risk RS cohort were less than $1 \%$ at both 5 and 9 years, which support the use of endocrine therapy alone in N1 cohort (9). Many oncologists have begun to incorporate 21-gene RS testing into their clinical practice for node-positive $\left(\mathrm{N}_{+}\right)$patients (10). Therefore, chemotherapy-decisions in ER+ breast cancer could be based on the RS results rather than on the patient's lymph node status. It is well known that not all nodal positive patients have the same survival benefit from adjuvant chemotherapy $(11,12)$. In the current clinical practice, adjuvant systemic chemotherapy is recommended, in addition to endocrine therapy, to the patients with $>4$ positive lymph nodes $(\mathrm{N} 2-3)$ disease $(5,7)$. However, there are no definite markers for predicting the benefits of chemotherapy for patients with $\mathrm{N} 2-3$ disease, and the 21-gene testing is not a routine recommendation for the patient subset in the ESMO, St. Gallen International Expert Consensus, and NCCN guidelines $(5-7,13)$. The current chemotherapy regimens used in breast cancer has various toxicities including common acute toxicity, leukaemogenicity, anthracycline cardiotoxicity, and persistent neurotoxicity (14). Thus, the aim of the present study was to investigate whether 21-gene RS testing could also provide clinically meaningful information regarding chemotherapy decision making and survival outcomes in women with N2-3 breast cancer.

\section{Methods}

\section{Patients}

This retrospective cohort study identified breast cancer patients who were registered in the Surveillance, Epidemiology, and End Results (SEER) database. The SEER database of the National Cancer Institute includes de-identified information for approximately $28 \%$ of all newly diagnosed patients with cancer in the United States (15). We identified patients if they met the following inclusion criteria: (I) pathologically diagnosed as having female breast cancer between 2004 and 2013; (II) $>4$ positive lymph nodes; and (III) ER positivity and available 21 -gene RS results. We excluded those with distant metastasis, unavailable race/ethnicity, grade, tumor stage, and progesterone receptor (PR) status. Patients receiving unknown surgical procedures were also excluded. The approval process of Institutional Review Board was waived because of the de-identified information of the patients included in the SEER.

\section{Measures}

We extracted the following clinicopathological and treatment variables from the SEER dataset: age, race/ ethnicity, histological subtypes, grade, tumor (T) stage, N status, PR status, 21-gene RS groups, surgical procedure, chemotherapy, and radiotherapy. The results of 21-gene RS testing were divided into the following three risk groups: low-risk (RS less than 18), intermediate-risk (RS 18 to 30), and high-risk (RS 31 and above) (3). The human epidermal growth factor receptor-2 (HER2) status was not included in the statistical analysis because the information of HER2 status was not routinely registered in SEER program before 
Table 1 Patient baseline clinicopathological and treatment characteristics

\begin{tabular}{|c|c|}
\hline Variables & $\mathrm{n}(\%)$ \\
\hline Age (mean $\pm S D)$ (years) & $60.4 \pm 12.6$ \\
\hline \multicolumn{2}{|l|}{ Race/ethnicity } \\
\hline Non-Hispanic White & $290(70.7)$ \\
\hline Non-Hispanic Black & $42(10.2)$ \\
\hline Hispanic (all races) & $53(12.9)$ \\
\hline Other & $25(6.1)$ \\
\hline \multicolumn{2}{|l|}{ Grade } \\
\hline Well differentiated & $78(19.0)$ \\
\hline Moderately differentiated & $229(55.9)$ \\
\hline Poorly/undifferentiated & $103(25.1)$ \\
\hline \multicolumn{2}{|l|}{ Histological subtype } \\
\hline Invasive ductal carcinoma & 262 (63.9) \\
\hline Invasive lobular carcinoma & $90(22.0)$ \\
\hline Other & $58(14.1)$ \\
\hline \multicolumn{2}{|l|}{ Tumor stage } \\
\hline $\mathrm{T} 1$ & $121(29.5)$ \\
\hline T2 & $223(54.4)$ \\
\hline T3 & $55(13.4)$ \\
\hline $\mathrm{T} 4$ & $11(2.7)$ \\
\hline \multicolumn{2}{|l|}{ Nodal stage } \\
\hline N2 & $321(78.3)$ \\
\hline N3 & $89(21.7)$ \\
\hline \multicolumn{2}{|l|}{ PR status } \\
\hline Negative & $45(11.0)$ \\
\hline Positive & $365(89.0)$ \\
\hline \multicolumn{2}{|l|}{ 21-gene recurrence score } \\
\hline Low & $191(46.6)$ \\
\hline Intermediate & $164(40.0)$ \\
\hline High & $55(13.4)$ \\
\hline \multicolumn{2}{|l|}{ Surgical procedure } \\
\hline Breast-conserving surgery & $155(37.8)$ \\
\hline Mastectomy & $255(62.2)$ \\
\hline \multicolumn{2}{|l|}{ Radiotherapy } \\
\hline No/unknown & $138(33.7)$ \\
\hline Yes & $272(66.3)$ \\
\hline \multicolumn{2}{|l|}{ Chemotherapy } \\
\hline No/unknown & $143(34.9)$ \\
\hline Yes & $267(65.1)$ \\
\hline
\end{tabular}

N, nodal; PR, progesterone receptor; SD, standard deviation; T, tumor.
2010. The definition of TNM stage was according to the sixth edition of the American Joint Committee on Cancer (AJCC) breast cancer staging system. The primary survival outcomes were BCSS and overall survival (OS). BCSS was estimated as time from initial diagnosis to date of breast cancer-specific death or last follow-up. OS was calculated as events including all cause of deaths.

\section{Statistical analysis}

The chi-squared test was used to compare variables among the three RS cohorts. The independent predictors related to chemotherapy receipt were assessed using binomial logistic regression, and their results were shown as odds ratios (ORs) with corresponding $95 \%$ confidence intervals (CIs). Survival curves were calculated using the Kaplan-Meier method and compared using log-rank tests. The independent prognostic factors related to survival outcomes were analyzed using multivariate Cox proportional hazards models, and their results were listed with hazards ratios (HRs) and 95\% CIs. Receiver operating characteristics (ROC) curve was also plotted, and the area under the curve (AUC) was calculated to assess the effect of 21 -gene RS in predicting the chemotherapy receipt and survival outcomes. Statistical analysis was conducted using IBM SPSS version 22.0 (IBM Corp., Armonk, NY, USA), and P values less than 0.05 were considered statistically significant.

\section{Results}

\section{Patient characteristics}

We included 410 patients in this study. The clinicopathological and treatment characteristics of the patients are listed in Table 1. Most of patients were Non-Hispanic White $(\mathrm{n}=290,70.7 \%)$, with moderately differentiated disease $(\mathrm{n}=229,55.9 \%)$, invasive ductal carcinoma subtype $(\mathrm{n}=262,63.9 \%)$, stage T1-2 $(\mathrm{n}=344$, $83.9 \%)$, and $\mathrm{N} 2$ stage ( $\mathrm{n}=321,78.3 \%)$. In addition, $89.0 \%$ of the patients had PR positive disease. Approximately two-thirds of the patients received mastectomy $(62.2 \%)$, radiotherapy $(66.3 \%)$, and chemotherapy $(65.1 \%)$. The median RS was 18 with a range of $0-81$, and 191 (46.6\%), $164(40.0 \%)$, and $55(13.4 \%)$ patients were classified into the low-, intermediate-, and high-risk RS groups, respectively. There are a total of 302 patients with HER2 status available, of which $94.0 \%(n=284)$ suffered from HER2 negative disease. 
Table 2 Multivariable logistic regression model for chemotherapy receipt

\begin{tabular}{|c|c|c|c|}
\hline Variables & OR & $95 \% \mathrm{Cl}$ & $\mathrm{P}$ \\
\hline Age (years) (mean $\pm S D)$ & 0.911 & $0.891-0.932$ & $<0.001$ \\
\hline \multicolumn{4}{|l|}{ Race/ethnicity } \\
\hline Non-Hispanic White & 1 & & \\
\hline Non-Hispanic Black & 0.873 & $0.359-2.125$ & 0.765 \\
\hline Hispanic (all races) & 0.488 & $0.238-1.000$ & 0.050 \\
\hline Other & 0.68 & $0.246-1.884$ & 0.459 \\
\hline \multicolumn{4}{|l|}{ Grade } \\
\hline Well differentiated & 1 & & \\
\hline Moderately differentiated & 1.432 & $0.747-2.746$ & 0.279 \\
\hline Poorly/undifferentiated & 0.903 & $0.402-2.030$ & 0.805 \\
\hline \multicolumn{4}{|l|}{ Histological subtype } \\
\hline Invasive ductal carcinoma & 1 & & \\
\hline Invasive lobular carcinoma & 0.801 & $0.428-1.498$ & 0.487 \\
\hline Other & 1.253 & $0.602-2.610$ & 0.547 \\
\hline \multicolumn{4}{|l|}{ Tumor stage } \\
\hline $\mathrm{T} 1$ & 1 & & \\
\hline $\mathrm{T} 2$ & 0.615 & $0.348-1.087$ & 0.095 \\
\hline T3 & 0.653 & $0.283-1.507$ & 0.317 \\
\hline $\mathrm{T} 4$ & 0.514 & $0.106-2.486$ & 0.408 \\
\hline \multicolumn{4}{|l|}{ Nodal stage } \\
\hline N2 & 1 & & \\
\hline N3 & 1.813 & $1.012-3.247$ & 0.045 \\
\hline \multicolumn{4}{|l|}{ PR status } \\
\hline Negative & 1 & & \\
\hline Positive & 0.639 & $0.270-1.512$ & 0.308 \\
\hline \multicolumn{4}{|l|}{ 21-gene recurrence score } \\
\hline Low & 1 & & \\
\hline Intermediate & 1.309 & $0.790-2.170$ & 0.296 \\
\hline High & 3.567 & $1.570-8.102$ & 0.002 \\
\hline \multicolumn{4}{|l|}{ Surgical procedure } \\
\hline Breast-conserving surgery & 1 & & \\
\hline Mastectomy & 0.493 & $0.299-0.812$ & 0.005 \\
\hline \multicolumn{4}{|l|}{ Radiotherapy } \\
\hline No/unknown & 1 & & \\
\hline Yes & 2.212 & $1.343-3.645$ & 0.002 \\
\hline
\end{tabular}

$\mathrm{Cl}$, confidence interval; $\mathrm{N}$, nodal; OR, odds ratio; $\mathrm{PR}$, progesterone receptor; T, tumor.

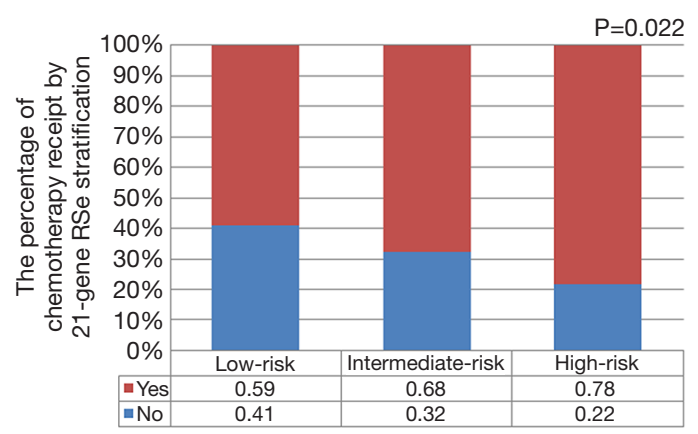

Figure 1 The percentage of chemotherapy receipt by 21-gene recurrence score stratification.

\section{Predictors related to chemotherapy receipt}

We used binomial logistic analysis to analyze the independent predictors associated with chemotherapy receipt (Table 2). The results indicated that the 21 -gene RS value was independently associated with the receipt of chemotherapy. Patients in the high-risk RS cohort was more likely to receive chemotherapy than those in the low-risk RS cohort (OR, 3.567, 95\% CI: 1.570-8.102, $\mathrm{P}=0.002$ ), while there was similar chance of chemotherapy receipt between intermediate- and low-risk RS groups (OR, 1.309, 95\% CI: 0.790-2.170, P=0.296). Figure 1 lists the percentages of the receipt of chemotherapy by 21 -gene RS stratification. A total of $59.0 \%, 68.0 \%$, and $78.0 \%$ of patients received chemotherapy in the low-, intermediate-, and high-risk RS groups, respectively. Moreover, younger patients, and those with stage N3 disease who had undergone BCS and radiotherapy, were also more likely to receive chemotherapy. The 21 -gene RS was also served as an effective predict indicator of chemotherapy receipt in this patient subset as shown by ROC analysis (Figure 2).

\section{Outcomes and prognostic analysis}

A total of 37 breast cancer-related deaths were observed, with a median follow-up of 47 months (range, 3-140 months). The 5 -year BCSS was $92.7 \%, 88.3 \%$, and $70.7 \%$ in patients with low-, intermediate-, and high-risk RS groups, respectively $(\mathrm{P}<0.001)$ (Figure $3 A$ ), and the 5 -year OS was $92.1 \%, 80.6 \%$, and $66.6 \%$, respectively $(\mathrm{P}<0.001)$ (Figure $3 B$ ).

We further analyzed the effect of 21 -gene RS value on outcomes using multivariate Cox analysis (Table 3). As adjusted by age, tumor grade, histology, $\mathrm{T}$ stage, $\mathrm{N}$ stage, PR stage, race/ethnicity, and treatment, the 21-gene RS value was an independent indicator related to survival 


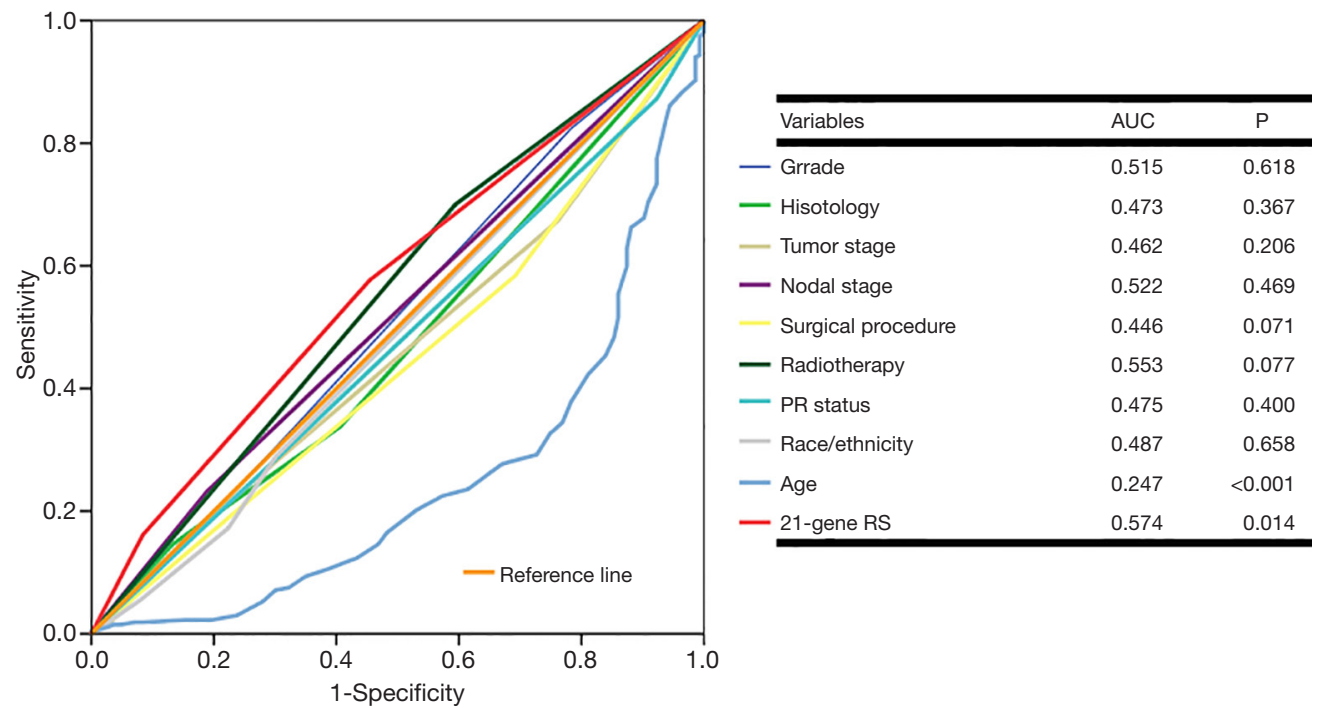

Figure 2 ROC analyses for prediction the chemotherapy receipt. ROC, receiver operating characteristics.
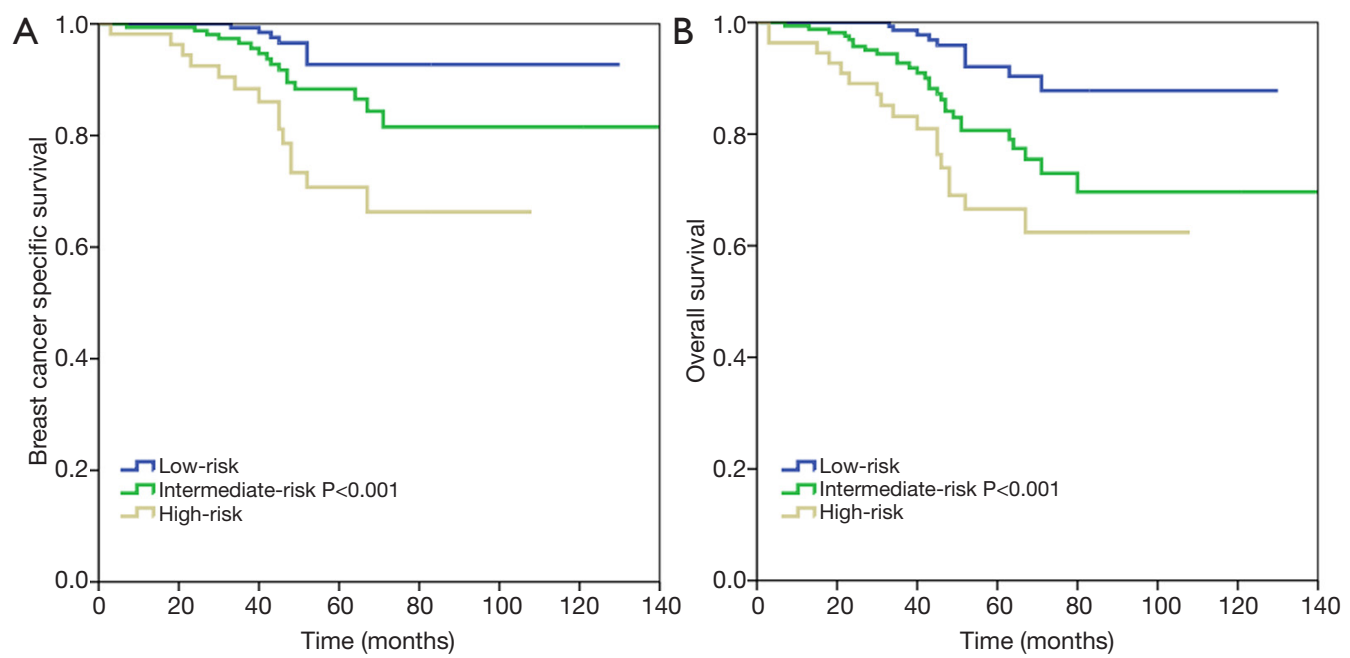

Figure 3 The breast cancer specific survival (A) and overall survival (B) by 21-gene RS stratification. RS, recurrence score.

outcomes. Patients with high-risk RS had the worst BCSS (HR, 6.440, 95\% CI: 2.597-15.974, $\mathrm{P}<0.001$ ) and OS (HR, 5.053, 95\% CI: $2.199-11.608, \mathrm{P}<0.001)$ compared with those in the low-risk RS group. Moreover, the intermediaterisk RS group also presented with lower BCSS (HR, 2.832, 95\% CI: $1.160-6.910, \mathrm{P}=0.022)$ and OS (HR, 3.704, 95\% CI: $1.750-7.836, \mathrm{P}=0.001)$ compared with those in the lowrisk group. Age and tumor grade were also independent prognostic factors associated with survival outcomes. The 21-gene RS was also served as an effective prognostic factor in this patient subset as shown by ROC analysis (Figure 4).

\section{Chemotherapy receipt and outcomes by 21-gene RS stratification}

Finally, we analyzed the effect of chemotherapy on survival outcomes by 21-gene RS stratification using multivariate cox analysis as adjusted by age, tumor grade, histology, T stage, $\mathrm{N}$ stage, PR stage, race/ethnicity, and treatment (Table 4). The results indicated that the receipt of chemotherapy was not related to better BCSS and OS in the low- and highrisk RS groups. However, the receipt of chemotherapy was associated with better OS in the intermediate-risk RS 
Table 3 Multivariate prognostic analyses in the entire cohort

\begin{tabular}{|c|c|c|c|c|c|c|}
\hline Variables & \multicolumn{3}{|c|}{ BCSS } & \multicolumn{3}{|c|}{ OS } \\
\hline Age (years) & 1.034 & $1.006-1.063$ & 0.018 & 1.041 & $1.015-1.068$ & 0.002 \\
\hline \multicolumn{7}{|l|}{ Race/ethnicity } \\
\hline Non-Hispanic White & 1 & & & 1 & & \\
\hline Non-Hispanic Black & 0.864 & $0.303-2.463$ & 0.785 & 1.575 & $0.697-3.557$ & 0.275 \\
\hline Other & 1.116 & $0.246-5.057$ & 0.887 & 1.098 & $0.321-3.749$ & 0.882 \\
\hline \multicolumn{7}{|l|}{ Grade } \\
\hline Well differentiated & 1 & & & 1 & & \\
\hline Moderately differentiated & 1.613 & $0.489-5.325$ & 0.432 & 2.637 & $0.905-7.685$ & 0.076 \\
\hline Invasive lobular carcinoma & 1.420 & $0.526-3.830$ & 0.489 & 1.954 & $0.910-4.199$ & 0.086 \\
\hline Other & 1.121 & $0.424-2.963$ & 0.818 & 1.003 & $0.432-2.331$ & 0.994 \\
\hline \multicolumn{7}{|l|}{ Tumor stage } \\
\hline $\mathrm{T} 1$ & 1 & & & 1 & & \\
\hline $\mathrm{T} 2$ & 1.064 & $0.459-2.466$ & 0.885 & 1.067 & $0.553-2.059$ & 0.847 \\
\hline T3 & 1.786 & $0.562-5.673$ & 0.326 & 1.509 & $0.562-4.051$ & 0.414 \\
\hline $\mathrm{T} 4$ & 2.441 & $0.542-10.988$ & 0.246 & 1.633 & $0.410-6.512$ & 0.487 \\
\hline \multicolumn{7}{|l|}{ Nodal stage } \\
\hline \multicolumn{7}{|l|}{ 21-gene recurrence score } \\
\hline Low & 1 & & & 1 & & \\
\hline Intermediate & 2.832 & $1.160-6.910$ & 0.022 & 3.704 & $1.750-7.836$ & 0.001 \\
\hline High & 6.440 & $2.597-15.974$ & $<0.001$ & 5.053 & $2.199-11.608$ & $<0.001$ \\
\hline \multicolumn{7}{|l|}{ Surgical procedure } \\
\hline Breast-conserving surgery & 1 & & & 1 & & \\
\hline Mastectomy & 1.055 & $0.504-2.209$ & 0.888 & 1.291 & $0.700-2.382$ & 0.414 \\
\hline \multicolumn{7}{|l|}{ Radiotherapy } \\
\hline No/unknown & 1 & & & 1 & & \\
\hline Yes & 0.981 & $0.470-2.048$ & 0.960 & 0.819 & $0.460-1.461$ & 0.499 \\
\hline \multicolumn{7}{|l|}{ Chemotherapy } \\
\hline No/unknown & 1 & & & 1 & & \\
\hline Yes & 0.648 & $0.292-1.441$ & 0.288 & 0.559 & $0.307-1.016$ & 0.056 \\
\hline
\end{tabular}

BCSS, breast cancer specific survival; $\mathrm{Cl}$, confidence interval; HR, hazards ratio; $\mathrm{N}$, nodal; OS, overall survival; PR, progesterone receptor; $\mathrm{T}$, tumor. 


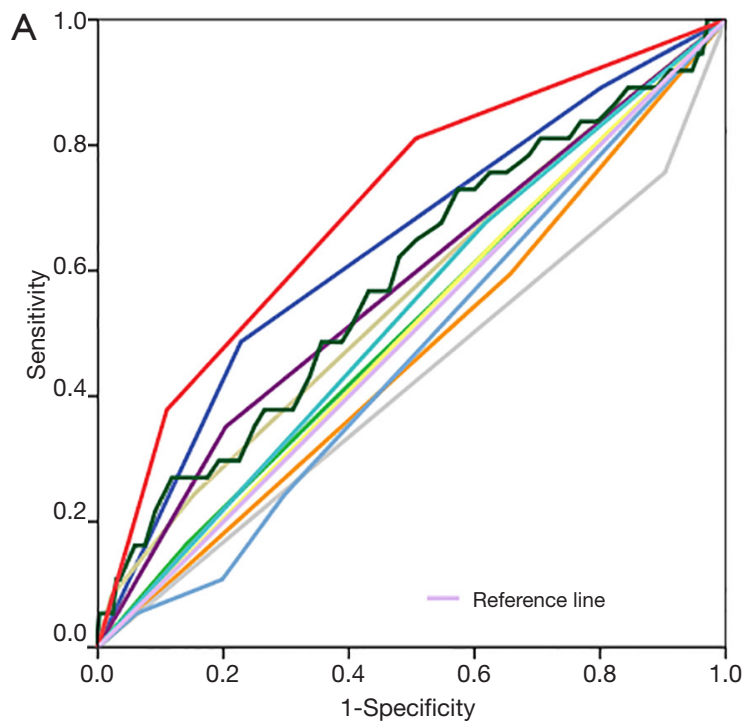

\begin{tabular}{lcc}
\hline Variables & AUC & $\mathrm{P}$ \\
\hline - Grrade & 0.639 & 0.005 \\
— Hisotology & 0.512 & 0.805 \\
— Tumor stage & 0.559 & 0.233 \\
- Nodal stage & 0.574 & 0.138 \\
- Radiotherapy & 0.507 & 0.892 \\
- Chemotherapy & 0.469 & 0.532 \\
- Surgical procedure & 0.530 & 0.553 \\
- PR status & 0.427 & 0.141 \\
- Race/ethnicity & 0.467 & 0.505 \\
- Age & 0.587 & 0.080 \\
- 21-gene RS & 0.703 & $<0.001$ \\
\hline
\end{tabular}

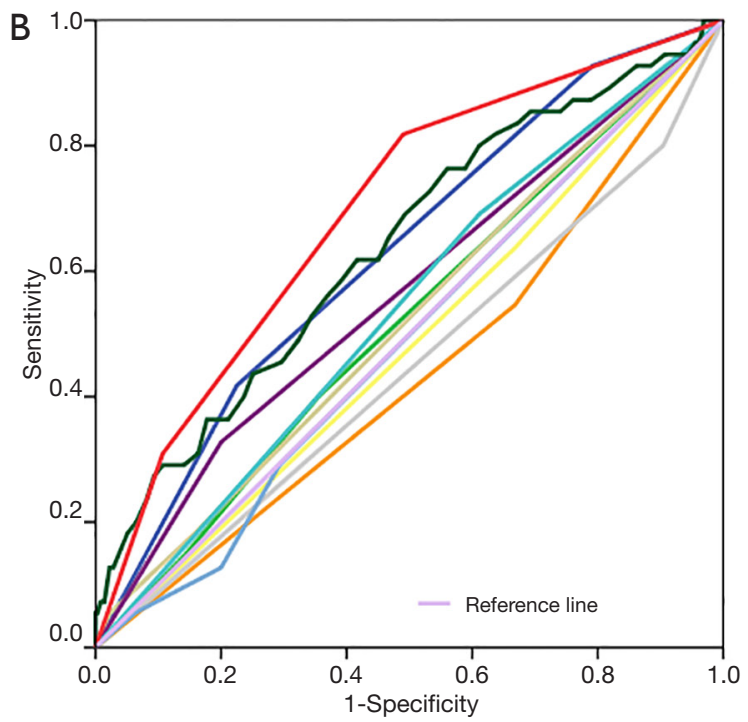

\begin{tabular}{lcc}
\hline Variables & AUC & $\mathrm{P}$ \\
\hline - Grrade & 0.629 & 0.002 \\
- Hisotology & 0.520 & 0.630 \\
- Tumor stage & 0.522 & 0.606 \\
- Nodal stage & 0.564 & 0.129 \\
- Radiotherapy & 0.484 & 0.709 \\
- Chemotherapy & 0.439 & 0.145 \\
- Surgical procedure & 0.540 & 0.342 \\
- PR status & 0.448 & 0.213 \\
- Race/ethnicity & 0.490 & 0.812 \\
- Age & 0.638 & 0.001 \\
- 21-gene RS & 0.696 & $<0.001$ \\
\hline
\end{tabular}

Figure 4 ROC analyses for prediction the breast cancer specific survival (A) and overall survival (B). ROC, receiver operating characteristics.

cohort (HR, 0.378, 95\% CI: 0.170-0.481, $\mathrm{P}=0.017$ ), but not to BCSS (HR, 0.576, 95\% CI: 0.143-2.327, $\mathrm{P}=0.439$ ). The 5 -year OS was $88.5 \%$ and $62.7 \%$ in patients with and without chemotherapy, respectively $(\mathrm{P}=0.006)$.

\section{Discussion}

In this study, we used data from SEER program to assess the role of 21-gene RS testing in women with N2-3 breast cancer. Our study showed that the 21-gene RS value was an independent indicator to predict chemotherapy receipt and survival outcome in this patient subset, which suggests that this genetic test may also be useful for the clinical management of this population.

Our previous study showed that the distribution of low, intermediate-, and high-risk RS in T1-2N0 ER positive invasive breast cancer was $56.7 \%, 35.7 \%$, and $7.6 \%$, respectively (16), which was consistent with the results for patients with N1 disease (17). Although a study from the Genomic Health laboratory found a similar distribution of 21-gene RS results among patients between N0 and $\mathrm{N}+$ diseases, the stratified analysis by nodal stage was not further performed (8). Similar to a previous study from the National Cancer Database and SEER (low-risk RS, 45.3$52.0 \%$; intermediate-risk RS, 31.7-41.1\%; high-risk RS, $13.7-16.3 \%)(17,18)$, we showed a higher chance of being 
Table 4 Multivariate prognostic analyses of chemotherapy receipt on survival outcomes by 21 -gene recurrence score stratification

\begin{tabular}{|c|c|c|c|c|c|c|}
\hline Variables & \multicolumn{3}{|c|}{ BCSS } & \multicolumn{3}{|c|}{ os } \\
\hline \multicolumn{7}{|l|}{ Low-risk } \\
\hline No & 1 & & & 1 & & \\
\hline Yes & 0.320 & $0.026-3.971$ & 0.375 & 0.605 & $0.052-7.089$ & 0.689 \\
\hline \multicolumn{7}{|c|}{ Intermediate-risk } \\
\hline No & 1 & & & 1 & & \\
\hline Yes & 0.576 & $0.143-2.327$ & 0.439 & 0.378 & $0.170-0.481$ & 0.017 \\
\hline \multicolumn{7}{|l|}{ High-risk } \\
\hline No & 1 & & & 1 & & \\
\hline
\end{tabular}

BCSS, breast cancer specific survival; Cl, confidence interval; HR, hazards ratio; OS, overall survival.

placed in the high-risk RS cohort in patients with stage N2-3 disease.

Previous studies on the prognostic value of 21 -gene RS have mainly focused on patients with N0 and N1 diseases (2,19-21). Few studies focused on patients with stage N2-3 disease $(22,23)$. A previous study from the NSABP B-20-trial showed a lower disease-free survival rate in the higher RS cohort (22). In addition, secondary analysis from the PACS01 parent trial also showed that the 21-gene RS value was associated with the risk of distant recurrence in patients with stage N2-3 disease (23). However, a study by Cockburn et al. using data from the Gene Expression Omnibus showed that the 21-gene RS value could significantly predict outcome for patients with $\mathrm{N} 0$ and $\mathrm{ER}+$ disease, but was unable to predict the risk of recurrence for patients with $\mathrm{N}+$ and $\mathrm{ER}+$ disease (24). Our results also showed lower BCSS and OS in patients with the intermediate- and high-risk RS cohorts than in the low-risk RS cohort. In addition, the effect of the 21-gene RS value to predict outcomes was superior to traditional prognostic factors, including tumor stage, nodal stage, PR status, and tumor grade. Our study has potential clinical implications for patients with stage N2-3 disease to refine the risk of distant metastasis and mortality. The genetic test could be useful to tailor the extent of clinical management in this patient subset and to identify those patients who could be candidates for further novel adjuvant therapies.

The current AJCC breast cancer staging system has incorporated 21-gene RS testing into the pathological prognostic stage in stage N0 breast cancer (25). A recent study from SEER showed that RS could also be incorporated into the pathological prognostic stage of patients with stage N1 disease (26). In our study, we adjusted the potential prognostic indicators of breast cancer, including $\mathrm{T}$ stage, $\mathrm{N}$ stage, grade, histology, and PR status, to validate the prognostic potential of the 21-gene RS. Thus, our study has optimized the method to predict outcomes in patients with stage N2-3 disease. These findings underscored the additional prognostic contribution of the 21-gene RS assay in the context of the traditional clinicopathological prognostic indicators in breast cancer.

Adjuvant chemotherapy has been the standard treatment in patients with stage $\mathrm{N} 2-3$ disease (7). In the present study, the 21-gene RS value was an independent predictor related to chemotherapy receipt. Patients with a higher RS were more likely to receive chemotherapy. Our findings showed that the 21-gene RS assay could also contribute to clinical management decisions in this population. However, the percentage of chemotherapy recommendation in the low- and intermediate-risk RS cohorts in our study was significantly higher than that in patients with stage N0-1 disease (2,19-21). Nearly $60 \%$ of the low-risk RS patients in our study were still treated with chemotherapy, whereas endocrine therapy is always recommended for low-risk RS patients with N0 disease. Interestingly, in the analysis of the effect of chemotherapy on survival outcomes by 21 -gene RS stratification, chemotherapy receipt was associated with better OS in patients with intermediate-risk RS, but was not associated with better survival outcomes in patients with low- and high-risk RS groups. These findings were quite 
different from the current results for patients with stage N0 disease $(1,2)$. The reason for this difference remains unclear. The small sample size of patients and shorter followup period of this study meant that we could not draw a conclusion between 21-gene RS and chemotherapy benefit in this cohort. The ongoing randomized phase III SWOG S1007 trial may provide valuable insights into the clinical management in patients with $\mathrm{N}+$ disease (27). However, only stage $\mathrm{N} 1$ patients with 21 -gene $\mathrm{RS} \leq 25$ were included in the randomized trial. Therefore, more studies are needed to investigate individualized treatment strategies in the clinical management of patients with higher tumor burdens.

Our study has certain limitations. First, the relatively limited number of patients included of this study is a reflection of the lack of national consensus on the use of the 21-gene RS test in this population. Second, the comorbidity of patients was also not recorded in SEER, which could potentially impact chemotherapy-decision marking. Third, the patterns of locoregional and distant recurrence were not collected in the SEER registries, making collection of the information regarding their outcomes impossible. Moreover, additional analyses including long-term followup are needed. Finally, there were underreporting of chemotherapy and radiotherapy use in the SEER database; therefore, such analyses were suboptimal. Approximately $15 \%$ of the patients in the observation cohort might also be treated with chemotherapy/radiotherapy that possibly impacted their survival outcomes (28). Although this bias cannot be ruled out, it was highly specific in patients who had chemotherapy and radiotherapy recorded. The primary strength of this study is that we have added to the current knowledge of supporting evidence that the 21-gene RS results are also independently related to survival outcomes in breast cancer patients with $\mathrm{N} 2-3$ disease.

\section{Conclusions}

In conclusion, our results demonstrate that the 21-gene RS value is an independent predictor of chemotherapy receipt and survival outcomes in breast cancer patients with N2-3 disease. Further prospective investigations are required to determine the selection of the optimal therapy for this patient subset according to the results of 21 -gene RS testing.

\section{Acknowledgments}

Funding: This work was partly supported by the National
Natural Science Foundation of China (81872459, 81803050), Natural Science Foundation of Fujian Province (No. 2016J01635) and the Science and Technology Planning Projects of Xiamen Science \& Technology Bureau (No. 3502Z20174070).

\section{Footnote}

Conflicts of Interest: The authors have no conflicts of interest to declare.

Ethical Statement: The approval process of Institutional Review Board was waived because of the de-identified information of the patients included in the SEER. The authors are accountable for all aspects of the work in ensuring that questions related to the accuracy or integrity of any part of the work are appropriately investigated and resolved.

\section{References}

1. Paik S, Tang G, Shak S, et al. Gene expression and benefit of chemotherapy in women with node-negative, estrogen receptor-positive breast cancer. J Clin Oncol 2006;24:3726-34.

2. Albain KS, Barlow WE, Shak S, et al. Prognostic and predictive value of the 21-gene recurrence score assay in postmenopausal women with node-positive, oestrogenreceptor-positive breast cancer on chemotherapy: a retrospective analysis of a randomised trial. Lancet Oncol 2010;11:55-65.

3. Wong WB, Ramsey SD, Barlow WE, et al. The value of comparative effectiveness research: projected return on investment of the RxPONDER trial (SWOG S1007). Contemp Clin Trials 2012;33:1117-23.

4. Krop I, Ismaila N, Andre F, et al. Use of Biomarkers to Guide Decisions on Adjuvant Systemic Therapy for Women With Early-Stage Invasive Breast Cancer: American Society of Clinical Oncology Clinical Practice Guideline Focused Update. J Clin Oncol 2017;35:2838-47.

5. Cardoso F, Kyriakides S, Ohno S, et al. Primary breast cancer: ESMO Clinical Practice Guidelines for diagnosis, treatment and follow-up. Ann Oncol 2019. doi: 10.1093/ annonc/mdz173.

6. Untch M, Thomssen C, Bauerfeind I, et al. Primary Therapy of Early Breast Cancer: Evidence, Controversies, Consensus: Spectrum of Opinion of German Specialists on the 16th St. Gallen International Breast Cancer 
Conference (Vienna 2019). Geburtshilfe Frauenheilkd 2019;79:591-604.

7. NCCN. NCCN clinical Practice guidelines in oncology V.2.2018. Breast Cancer. (2018) Available online: https:// www.nccn.org/professionals/physician_gls/pdf/breast.pdf (Access OCT 21, 2018).

8. Bello DM, Russell C, McCullough D, et al. Lymph Node Status in Breast Cancer Does Not Predict Tumor Biology. Ann Surg Oncol 2018;25:2884-9.

9. Hortobagyi GN, Shak S, Sledge GW Jr, et al. Breast cancer specific mortality (BCSM) in patients (pts) with node-negative (N0) and node-positive breast cancer (BC) guided by the 21-gene assay: A SEER-genomic population-based study. In: (P3-11-02) San Antonio Breast Cancer Symposium 2018.

10. Mittendorf EA, King TA. Routine Use of Oncotype DX Recurrence Score Testing in Node-Positive Hormone Receptor-Positive HER2-Negative Breast Cancer: The Time Has Come. Ann Surg Oncol 2019;26:1173-5.

11. Early Breast Cancer Trialists' Collaborative Group (EBCTCG), Peto R, Davies C, et al. Comparisons between different polychemotherapy regimens for early breast cancer: meta-analyses of long-term outcome among 100,000 women in 123 randomised trials. Lancet 2012;379:432-44.

12. Early Breast Cancer Trialists' Collaborative Group (EBCTCG). Effects of chemotherapy and hormonal therapy for early breast cancer on recurrence and 15 year survival: an overview of the randomised trials. Lancet 2005;365:1687-717.

13. Natsuhara KH, Losk K, King TA, et al. Impact of Genomic Assay Testing and Clinical Factors on Chemotherapy Use After Implementation of Standardized Testing Criteria. Oncologist 2019;24:595-602.

14. Azim HA Jr, de Azambuja E, Colozza M, et al. Long-term toxic effects of adjuvant chemotherapy in breast cancer. Ann Oncol 2011;22:1939-47.

15. Surveillance, Epidemiology, and End Results (SEER) Program (www.seer.cancer.gov) SEER*Stat Database: Incidence - SEER 18 Regs (Excl AK) Custom Data Malignant Breast (with Oncotype DX and Additional Treatment Fields), Nov 2017 Sub (2004-2015) - Linked To County Attributes - Total U.S., 1969-2016 Counties, National Cancer Institute, DCCPS, Surveillance Research Program, released April 2018, based on the November 2017 submission.

16. Wang J, He ZY, Dong Y, et al. The Distribution and Outcomes of the 21-Gene Recurrence Score in T1-T2N0
Estrogen Receptor-Positive Breast Cancer With Different Histologic Subtypes. Front Genet 2018;9:638.

17. Roberts MC, Miller DP, Shak S, et al. Breast cancerspecific survival in patients with lymph node-positive hormone receptor-positive invasive breast cancer and Oncotype DX Recurrence Score results in the SEER database. Breast Cancer Res Treat 2017;163:303-10.

18. Orucevic A, Heidel RE, Bell JL. Utilization and impact of 21-gene recurrence score assay for breast cancer in clinical practice across the United States: lessons learned from the 2010 to 2012 National Cancer Data Base analysis. Breast Cancer Res Treat 2016;157:427-35.

19. Torres S, Trudeau M, Gandhi S, et al. Prospective Evaluation of the Impact of the 21-Gene Recurrence Score Assay on Adjuvant Treatment Decisions for Women with Node-Positive Breast Cancer in Ontario, Canada. Oncologist 2018;23:768-75.

20. Stemmer SM, Klang SH, Ben-Baruch N, et al. The impact of the 21-gene Recurrence Score assay on clinical decisionmaking in node-positive (up to 3 positive nodes) estrogen receptor-positive breast cancer patients. Breast Cancer Res Treat 2013;140:83-92.

21. Dowsett M, Cuzick J, Wale C, et al. Prediction of risk of distant recurrence using the 21-gene recurrence score in node-negative and node-positive postmenopausal patients with breast cancer treated with anastrozole or tamoxifen: a TransATAC study. J Clin Oncol 2010;28:1829-34.

22. Mamounas EP, Tang G, Paik S, et al. 21-Gene Recurrence Score for prognosis and prediction of taxane benefit after adjuvant chemotherapy plus endocrine therapy: results from NSABP B-28/NRG Oncology. Breast Cancer Res Treat 2018;168:69-77.

23. Penault-Llorca F, Filleron T, Asselain B, et al. The 21gene Recurrence Score $®$ assay predicts distant recurrence in lymph node-positive, hormone receptor-positive, breast cancer patients treated with adjuvant sequential epirubicinand docetaxel-based or epirubicin-based chemotherapy (PACS-01 trial). BMC Cancer 2018;18:526.

24. Cockburn JG, Hallett RM, Gillgrass AE, et al. The effects of lymph node status on predicting outcome in ER+ / HER2 - tamoxifen treated breast cancer patients using gene signatures. BMC Cancer 2016;16:555.

25. Hortobagyi GN, Edge SB, Giuliano A. New and Important Changes in the TNM Staging System for Breast Cancer. Am Soc Clin Oncol Educ Book 2018;38:457-67.

26. Wang M, Wu K, Zhang P, et al. The Prognostic Significance of the Oncotype DX Recurrence Score in T1-2N1M0 Estrogen Receptor-Positive HER2- 
Negative Breast Cancer Based on the Prognostic Stage in the Updated AJCC 8th Edition. Ann Surg Oncol 2018;26:1227-35.

27. Ramsey SD, Barlow WE, Gonzalez-Angulo AM, et al. Integrating comparative effectiveness design elements and endpoints into a phase III, randomized clinical trial (SWOG S1007) evaluating oncotype DX-guided management for women with breast cancer involving lymph nodes. Contemp Clin Trials 2013;34:1-9.

28. Noone AM, Lund JL, Mariotto A, et al. Comparison of SEER Treatment Data With Medicare Claims. Med Care 2016;54:e55-64.

Cite this article as: Zhang QH, Zhang WW, Wang J, Lian CL, Sun JY, He ZY, Wu SG. Impact of the 21-gene recurrence score assay on chemotherapy decision making and outcomes for breast cancer patients with four or more positive lymph nodes. Ann Transl Med 2019;7(18):446. doi: 10.21037/atm.2019.08.82 